\section{Hot air - or what?}

\section{Boston}

STEPHEN Schneider, of the National Center for Atmospheric Research, faced off against Richard Lindzen of Massachusetts Institute of Technology (MIT) last week in a debate at MIT entitled "Is it getting hotter or what?" Schneider supports the view that current climate models can reasonably predict a mean rise in global temperatures of $2{ }^{\circ} \mathrm{C}$ or more over the next century; Lindzen is an increasingly vociferous critic of the inadequacies of current climate models.

At the debate, Lindzen argued that current models are weak, and that a warming trend remains to be seen in the recent temperature data. The picture presented by Schneider and others is "misleading," principally because present climatological models are "inconsistent with observations of landbased global average temperatures", contain documented errors, and have made a poor job of predicting climate change in the tropics.

Furthermore, Lindzen said, climate models do not adequately account for the role of feedback from the oceans. Lindzen stressed the role of convection in the upper atmosphere that allows heat to escape by circulating vertically. Those who predict global warming, he maintained, emphasize only the atmosphere's radiative features for heating and cooling the Earth. "The effectiveness of our greenhouse is just 25 per cent", he said, adding that if it were much more effective, the Earth's temperatures would be far higher - in the vicinity of $77^{\circ} \mathrm{C}$. In particular, Lindzen cited research on the transport of water vapour in the atmosphere, stating that current transport models are "off by a factor of two." Lindzen maintains that the parameters used by current models "exaggerate the moisturization of the upper troposphere". In the models, he says, much of the predicted warming comes from atmospheric humidity which traps the Earth's heat. Given the extent of the many uncertainties, Lindzen stated, cause for alarm should come only when observed temperatures are shown to clearly be higher than can be predicted by normal deviation.

In his rebuttal, Schneider acknowledged that the issues raised by Lindzen are legitimate, and questioned whether the combined effects of different errors could all be working together, but might instead "cancel each other out." Despite all the uncertainties presented, Schneider felt that it is "unlikely that the models are off by more than a factor of three," a fact which would greatly alter the perceived increase in temperature, but not negate altogether the possibility of a significant temperature increase.

But on balance, even these two re- searchers, representing the far ends of the spectrum of current debate within the community of atmospheric researchers, ended up agreeing on more points than than they might have otherwise acknowledged. Schneider readily acknowledged that current models are neither particularly accurate nor reliable. Lindzen, for his part, agreed upon the need for intensified research efforts, if only "to find out why the models are wrong". As for the policy questions of how to respond in the face of such uncertainty - these were left for several social scientists who spoke later in the event's programme. Amidst sketchy discussion of the possibility of such things as a "world carbon budget", perhaps the best prescription came from MIT economist Henry Jacoby. If the threat of global warming can wean the planet off of its harmful greenhouse gasproducing ways, he said, it can thereby encourage us to do those things we probably "ought to be doing anyway." As Jacoby put it, in the face of potential global warming the answer is evident: "repent."

Seth Shulman

\title{
Urgent action still opposed
}

\section{London}

WORKING group III of the Intergovernmental Panel on Climate Change (IPCC) emerged at the end of its Geneva meeting last week with its suggestions for carbon dioxide emissions fundamentally unchanged from the widely-criticized measures outlined in an early leaked draft of the report (see Nature 345, 373, 31 May 1990). The US-chaired group III examined possible responses to the threat of global warming and has been accused by environmentalists of ignoring scientific evidence and simply following the policy of member governments.

In response to pressure from governments already committed to emission cuts and the consensus arrived at by the climatologists of working group I, the repeated references in the leaked draft to the "scientific uncertainties" surrounding global warming are reduced in the final version. But Paul Hohnen from Greenpeace International, an observer at the meeting, says group III's report may still be "all things to all persons", and provide

\section{CFCs}

\section{Britain going CFC-free?}

\section{London}

BRITAIN could eliminate almost all chlorofluorocarbon (CFC) use by 1997 at "relatively little cost", according to a report sponsored by the Department of Trade and Industry. A team of consultants led by Coopers \& Lybrand Deloitte found that British CFC use had already halved between 1986 and 1989.

Although use of ozone-damaging halons had increased slightly over the same period, trade and industry minister Eric Forth said Britain had met its commitment to the Montreal Protocol "almost ten years ahead of requirements". The report would be made available to delegates attending a meeting in London later this month to strengthen the Montreal Protocol, he said.

Peter Aldhous an excuse for inactivity on the part of governments reluctant to curb emissions.

The Geneva meeting again saw US, Canadian, Soviet and Japanese representatives (joined by oil-rich Saudia Arabia, in its first significant contribution to the global warming debate) opposing Western European countries that want to set reduced greenhouse gas emissions targets early on. Scandinavian nations, backed by others including the Netherlands, France and Italy, tried unsuccesfully to insert into the report a line noting that some countries want negotiations towards a protocol on greenhouse gases to start immediately rather than waiting for IPCC to draw together the conclusions from its three working groups.

European Communities (EC) environment ministers, meeting last week in Luxembourg, delayed setting targets on greenhouse emissions. Together with environment commissioner Carlo Ripa di Meana, West Germany, France and Holland had called for EC member states to stabilize emissions at current levels by 2000. But Britain, Spain, Portugal and Greece refused to back this measure, ministers instead adopting an Irish suggestion for countries to establish national strategies to curb emissions, before discussing the issue again in October.

Before the EC meeting, British Labour opposition environment spokesman Bryan Gould labelled prime minister Margaret Thatcher's recent pledge to stabilize UK emissions at present levels by 2005 as "a gigantic confidence trick". Thatcher's statement that this target involved undercutting projected emissions by up to 30 per cent was based on a "far-fetched" Department of Energy study, which assumes that Britain will recover all of the energyintensive heavy industry lost during the economic recession of the $1970 \mathrm{~s}$, Gould said. He added that a Labour government would stabilize emissions by 2000 , but did not say exactly how this would be achieved.

Peter Aldhous 